\title{
Thermo-mechanical tests on W7-X current lead flanges
}

\author{
Chandra Prakash Dhard, Thomas Rummel, Daniel Zacharias, Victor Bykov \\ Thomas Moennich, Klaus-Peter Buscher \\ Max-Planck-Institut fuer Plasmaphysik, Greifswald Branch, Euratom Association, \\ Wendelsteinstrasse 1, D-17491 Germany
}

\begin{abstract}
Fourteen pieces of high temperature superconducting current leads (CL) arranged in seven pairs, will be installed on the outer vessel of Wendelstein 7-X (W7-X) stellarator. In order to support the CL, it is provided with two glass fibre reinforce plastic (GFRP) flanges, namely, the lower cryostat flange (CF) remaining at room temperature and upper radial flange (RF) at about $5 \mathrm{~K}$. Both the flanges i.e. CF \& RF experience high mechanical loads with respect to the CL, due to the evacuation of W7-X cryostat, cool-down of cold mass including the CL, electro-magnetic forces due to current \& plasma operations and self weight of CL. In order to check the integrity of these flanges for such mechanical loads, thermo-mechanical tests were carried out on these flanges at room temperatures and at liquid nitrogen (LN2) temperatures. The details of test set-up, results and modeling are described in the paper.
\end{abstract}

Keywords: Wendelstein 7-X; Current leads; Thermo-mechanical tests

\section{Introduction}

Due to the optimization of peripheral components surrounding W7-X it was decided to mount the CL at the bottom of the cryostat itself, therefore, these are mounted in upside down configuration with warm end at the bottom connected to the room temperature (RT) power supply and cold end at the top joined to superconducting bus bars. Seven pairs of leads are used to power 50 non-planar and 20 planar superconducting coils arranged in seven independent circuits with ten coils in each circuit. Coils are charged with $18.2 \mathrm{kA}$ and $14 \mathrm{kA}$ currents in peak power and standard modes of operations to generate magnetic fields of $3 \mathrm{~T}$ and $2.5 \mathrm{~T}$ respectively within the plasma vessel. The leads are developed by the Karlsruhe Institute of Technology (KIT), Karlsruhe, Germany, which are based on the high temperature superconductors at the top end and conventional copper heat exchanger at the bottom. The leads are designed for the maximum current of $18.2 \mathrm{kA}$ and built with their own vacuum insulation. The schematic of leads is shown in figure 1 , showing the joint box at the top enclosing the joint between the lead and the bus bars connecting to the coil circuits.

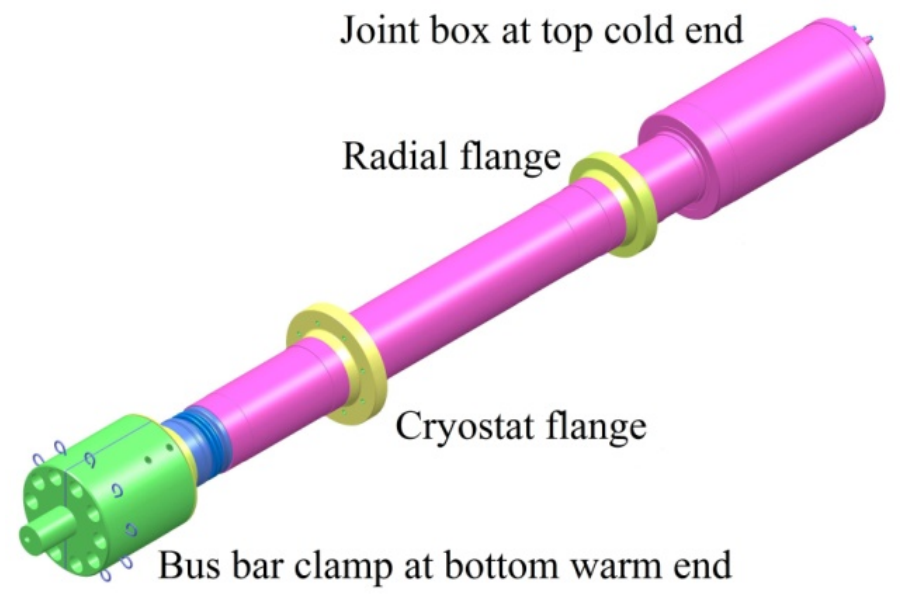

Fig.1 Schematics of W7-X current lead. 


\section{CL assembly and mechanical loads}

\subsection{CL assembly}

The leads are installed on the bottom dome of outer vessel by the CF with a vacuum tight sealing. The RF is supported on the stainless steel (SS) structure called fixing box. Both the leads of a pair are assembled together with a common Pivot point at the bottom and fixing box at the top. As shown in figure 2, the fixing box is connected to the W7-X central support structure with rotating flexible joints [1-2]. The bus bars close to leads are also supported on the fixing box. The supercritical helium $(<4.5 \mathrm{~K})$ and $50 \mathrm{~K}$ helium pipings are connected at the top end of leads and routed through the electrical isolators.

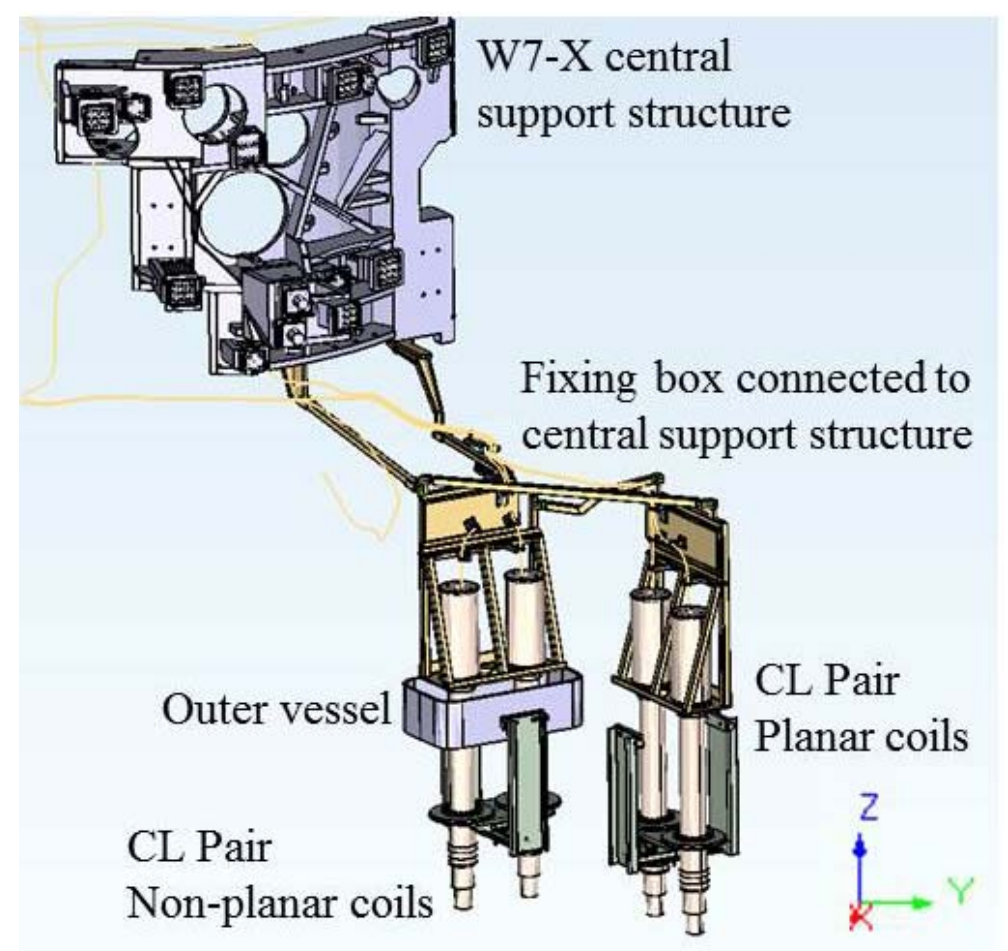

Fig.2 Assembly of CL pairs on W7-X cryostat.

\subsection{Mechanical loads}

Large mechanical loads are exerted on the leads because of movement of outer vessel due to evacuation, shrinking of central support structure due to cool down to $4.5 \mathrm{~K}$ temperatures, electromagnetic loads due to current and plasma operations and the weight of the leads itself. The estimated resulting forces $\left(F_{x}, F_{y} \& F_{z}\right)$ and moments $\left(M_{x}, M_{y}\right.$ \& $\left.M_{z}\right)$ on CF and RF generated in all the three directions (X, Y \& Z axes) are presented in table 1\&2 [1-2]. $\mathrm{F}_{\mathrm{Z}}$ is largest for case with double fixing boxes joined together. In order to take care of calculation uncertainties a safety factor of 1.5 is included.

Table 1: Values of forces exerted on CF at ambient temperature and RF at $5 \mathrm{~K}$ including a safety factor of 1.5

\begin{tabular}{cccc}
\hline Flange & $\mathrm{F}_{\mathrm{x}}$ & $\mathrm{F}_{\mathrm{y}}$ & $\mathrm{F}_{\mathrm{z}}$ \\
& $(\mathrm{N})$ & $(\mathrm{N})$ & $(\mathrm{N})$ \\
\hline $\mathrm{CF}$ & +313 & +538 & +8938 \\
$\mathrm{RF}$ & -563 & -538 & -1688 \\
\hline
\end{tabular}

For the construction of GFRP flanges for these loads it was necessary to prove the strength of the glue joint connecting the flanges to the SS pipe surface of the leads for such high mechanical loads. Therefore it was decided to carry out the mechanical tests in warm as well as in cold condition on the flange assembly of the actual dimensions to be used for the leads. 
Table 2: Values of moments exerted on CF at ambient temperature and RF at $5 \mathrm{~K}$ including a safety factor of 1.5

\begin{tabular}{lccc}
\hline Flange & $\begin{array}{c}\mathrm{M}_{\mathrm{x}} \\
(\mathrm{Nm})\end{array}$ & $\begin{array}{c}\mathrm{M}_{\mathrm{y}} \\
(\mathrm{Nm})\end{array}$ & $\begin{array}{c}\mathrm{M}_{\mathrm{z}} \\
(\mathrm{Nm})\end{array}$ \\
\hline $\mathrm{CF}$ & -450 & -588 & -588 \\
$\mathrm{RF}$ & +775 & +688 & +588 \\
\hline
\end{tabular}

\section{Test piece and modeling}

\subsection{Test piece}

The test piece was built as per the actual dimensions of SS pipe (o.d. $180 \mathrm{~mm}$ ), GFRP flange (i.d. $190 \mathrm{~mm}$, thickness $40 \mathrm{~mm}$ ) as used for CF of the leads. The SS

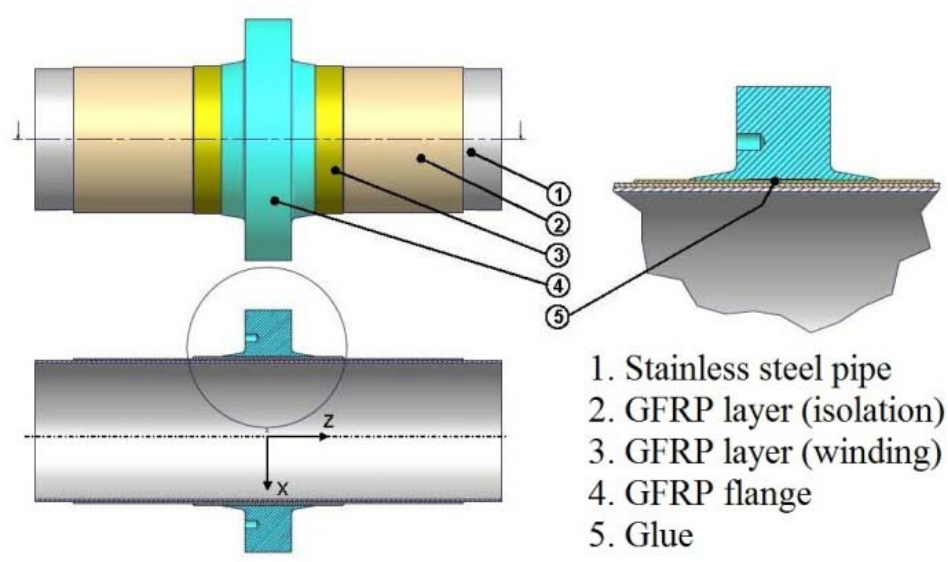

Fig.3 Schematics of flange test piece.

pipe of length $430 \mathrm{~mm}$ was closed from both sides keeping a port for evacuation at one end. The ground GFRP isolation layer was wound on the SS pipe, over which the flange was glued. To provide additional strength to the flange additional GFRP winding was made on both sides. It was decided to make the test piece of CF only and use it for both the loads i.e. at RT for CF loads and at $77 \mathrm{~K}$ for RF loads, since CF being bigger in diameter than RF, it was more conservative to test it for RF loads. The loads at RF are occurring at about $5 \mathrm{~K}$, however since below $77 \mathrm{~K}$ the thermal contraction is minimal therefore it was found to be sufficient to carry out the tests at $77 \mathrm{~K}$, moreover the test set-up at $77 \mathrm{~K}$ was much easier using LN2 compared to $5 \mathrm{~K}$ using liquid helium.

Altogether five test pieces were prepared with two different gluing techniques with different surface preparations and epoxy resins. Three pieces prepared with the first technique, were checked with helium leak test and Paschen test for their integrity and found OK. One of these pieces was subjected to the thermal cycling at $77 \mathrm{~K}$, which showed cracks at the glue joint location. Later the helium leak test showed large leakages. Therefore with the changed glue technique, two additional test pieces were prepared for tests at RT and $77 \mathrm{~K}$. One of these was subjected to similar tests as for the previous test piece as mentioned above and found to be OK. These flanges were then used for the thermomechanical load tests further.

\subsection{Modeling}

Using the actual dimensions of the test piece the finite element (FE) model was built, and the existing material properties of SS and GFRP were used for the estimations (see figure 4). For RT calculations, the resulting stresses due to all the forces and moments listed in table $1 \& 2$, were found to be well within the ultimate strengths of the respective materials. However the calculations at lower temperatures for RF loads, at some node locations at the interface between GFRP layer and SS, the resulting stress were found to be critical, it was therefore necessary to carry out the mechanical tests, especially at lower temperatures. 


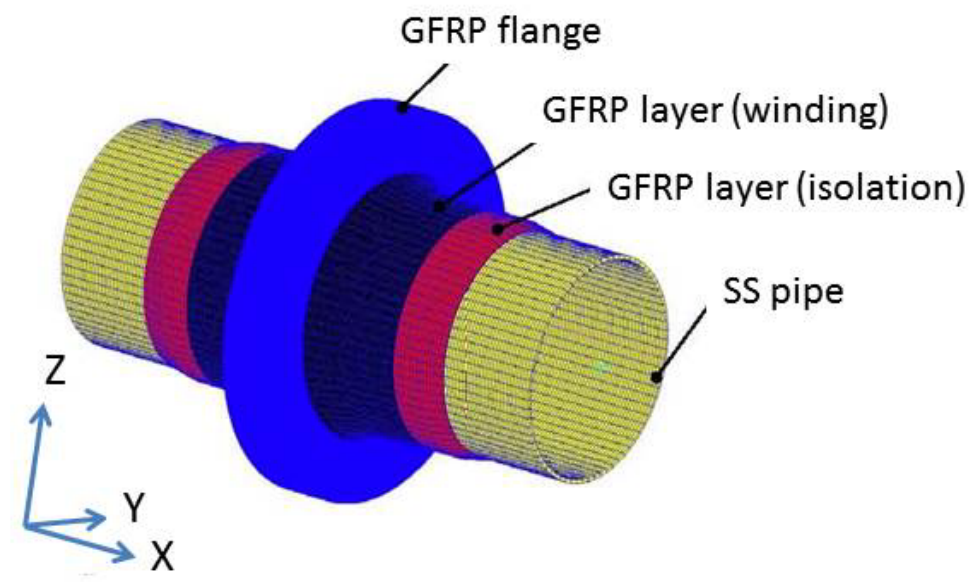

Fig.4 FE model of flange test piece.

\section{Test concept and set-up for measurements}

\subsection{Test concept}

On the test set-up in order to apply all the six loads (see table 1 \& 2), one requires several loading cylinders, making the test complex, therefore by superposition of loads, the number of loading cylinders were optimized to simplify the tests. Due to the circular shape of the flange test piece it is symmetric for rotation in X-Y plane, therefore the loads in $\mathrm{X}-\mathrm{Y}$ directions could be reduced as

$$
\begin{array}{crc}
\mathrm{F}_{\mathrm{x}} \& \mathrm{~F}_{\mathrm{y}} \rightarrow \mathrm{F}_{\mathrm{xy}}, & \text { and } & \mathrm{M}_{\mathrm{x}} \& \mathrm{M}_{\mathrm{y}} \rightarrow \mathrm{M}_{\mathrm{xy}} \cdot \\
\mathrm{M}_{\mathrm{xy}}=2 \cdot \mathrm{F}_{\mathrm{Mxy}} \cdot \mathrm{r} 1 & \text { Further, } & \\
\mathrm{F}_{\mathrm{a}}=\mathrm{F}_{\mathrm{z}} / 2-\mathrm{F}_{\mathrm{Mxy}} & \text { and } & \mathrm{M}_{\mathrm{z}}=\mathrm{F}_{\mathrm{Mz}} \cdot \mathrm{r} 2 \\
& \text { and } & \mathrm{F}_{\mathrm{b}}=\mathrm{F}_{\mathrm{z}} / 2+\mathrm{F}_{\mathrm{Mxy}} \\
& \mathrm{F}=\mathrm{F}_{\mathrm{a}}+\mathrm{F}_{\mathrm{b}}=\mathrm{F}_{\mathrm{z}} . &
\end{array}
$$

The terms r1, r2, a, b, F and $\mathrm{F}_{\mathrm{Mz}}$ are shown in figure 5, and the calculated values of these parameters for RT and $77 \mathrm{~K}$ loads are presented in table 3 . Thus, all the six loads could be applied by two forces i.e. F (in the axial direction) and $\mathrm{F}_{\mathrm{Mz}}$ (in the tangential direction) simplifying the test set-up [3].

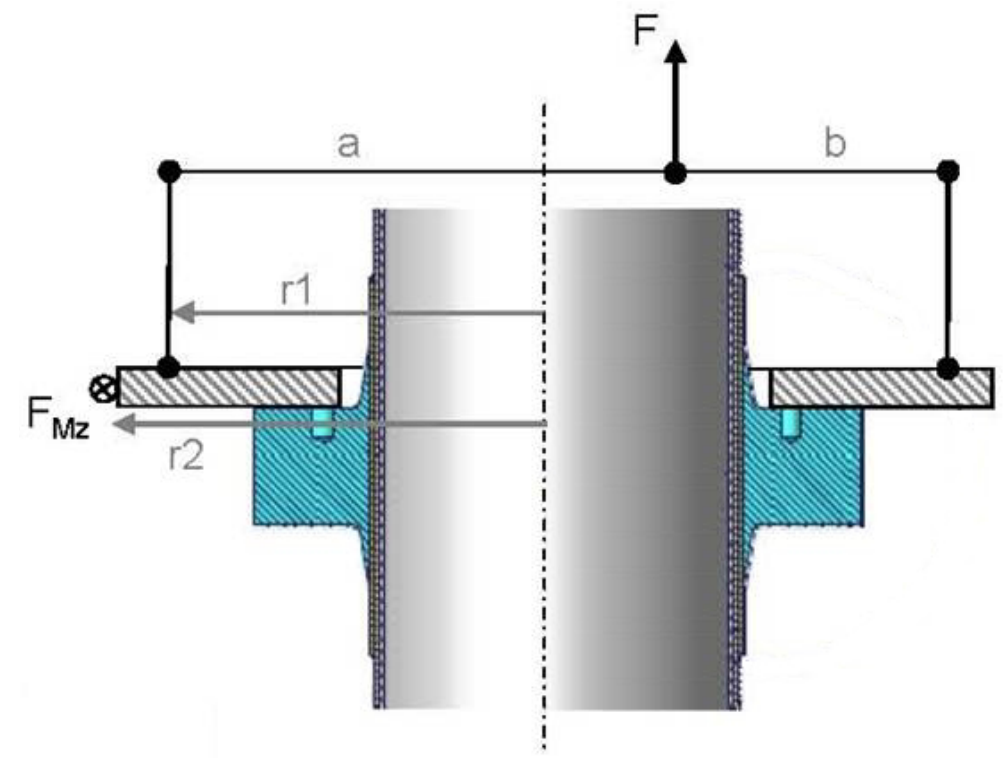

Fig.5 Reduced forces and their exerting locations on test piece. 
Table 3: Parameters for forces and their locations exerted on CF at RT and at 77 K including a safety factor of 1.5

\begin{tabular}{lcccccc}
\hline & $\begin{array}{c}\mathrm{r} 1 \\
(\mathrm{~mm})\end{array}$ & $\begin{array}{c}\mathrm{r} 2 \\
(\mathrm{~mm})\end{array}$ & $\begin{array}{c}\mathrm{a} \\
(\mathrm{mm})\end{array}$ & $\begin{array}{c}\mathrm{b} \\
(\mathrm{mm})\end{array}$ & $\begin{array}{c}\mathrm{F} \\
(\mathrm{N})\end{array}$ & $\begin{array}{c}\mathrm{F}_{\mathrm{Mz}} \\
(\mathrm{N})\end{array}$ \\
\hline $\mathrm{RT}$ & 280 & 280 & 197 & 363 & 8938 & 2100 \\
$77 \mathrm{~K}$ & 614 & 280 & 1228 & 0 & 1688 & 2100 \\
\hline
\end{tabular}

\subsection{Set-up for measurement}

On the GFRP flange the SS disc was fixed using Helicoil screws as planned to be done for actual assembly of leads. The SS disc was then fixed to a layout of beams connecting to the force exerting cylinders. Force $\mathrm{F}$ was applied by the hydraulic cylinders however $\mathrm{F}_{\mathrm{Mz}}$ was applied by manually adjustable tensioning device. The values of the forces

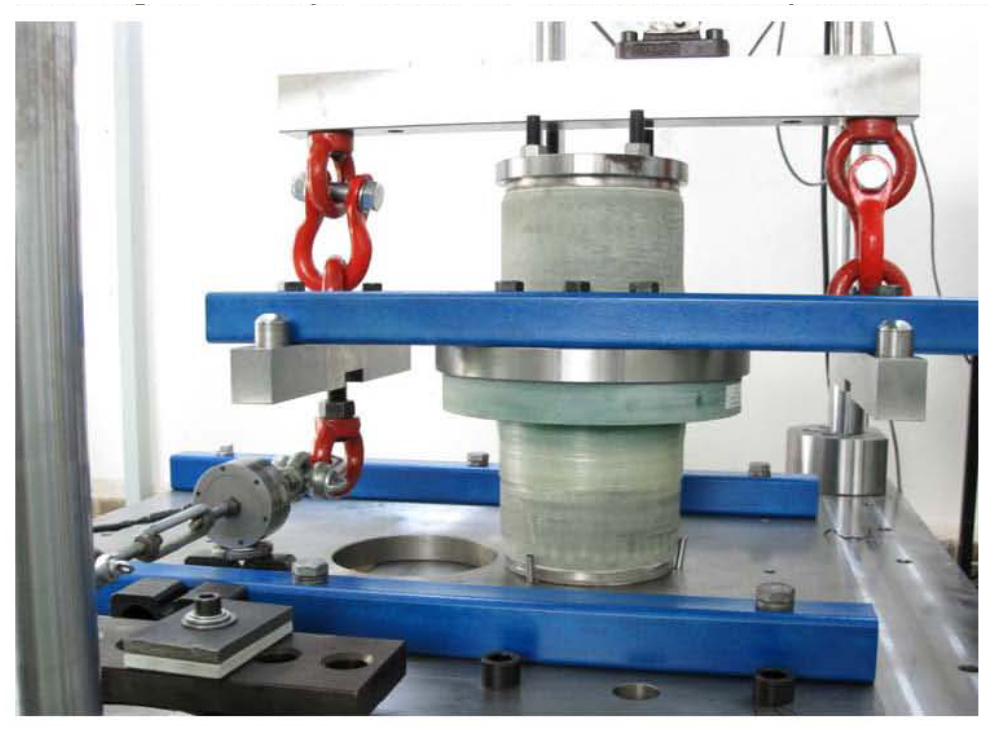

Fig.6 Schematics of test set-up at room temperature (RT) for the parameters mentioned in table 3.

applied and the displacement were measured by the precision instruments. The forces were applied in five steps i.e. 50\%-75\%-100\%-120\%-150\% in order to have a hold in case any deformation is observed at intermediate stages. For the RT measurements the set-up is shown in figure 6.

For the set-up at $77 \mathrm{~K}$ measurements, five temperature sensors were installed on the test piece and three is the vessel surrounding the test piece, additionally a heater was installed in the vessel. The vessel was built around the test piece measurement set-up and the cool-down to $77 \mathrm{~K}$ to be achieved using LN2 as shown in figure 7. A slow cool-down rate of about $15 \mathrm{~K} / \mathrm{h}$ was planned by manually regulating the LN2 flow and heater power. A maximum temperature difference across the test pieces needed to be maintained within $40 \mathrm{~K}$. After achieving the cool-down, the temperatures of $77 \mathrm{~K}$ were ensured at all the measuring points by supplying LN2 throughout the measurement. Load cycles were applied only after ensuring a steady temperature of $77 \mathrm{~K}$ at all locations [3]. 


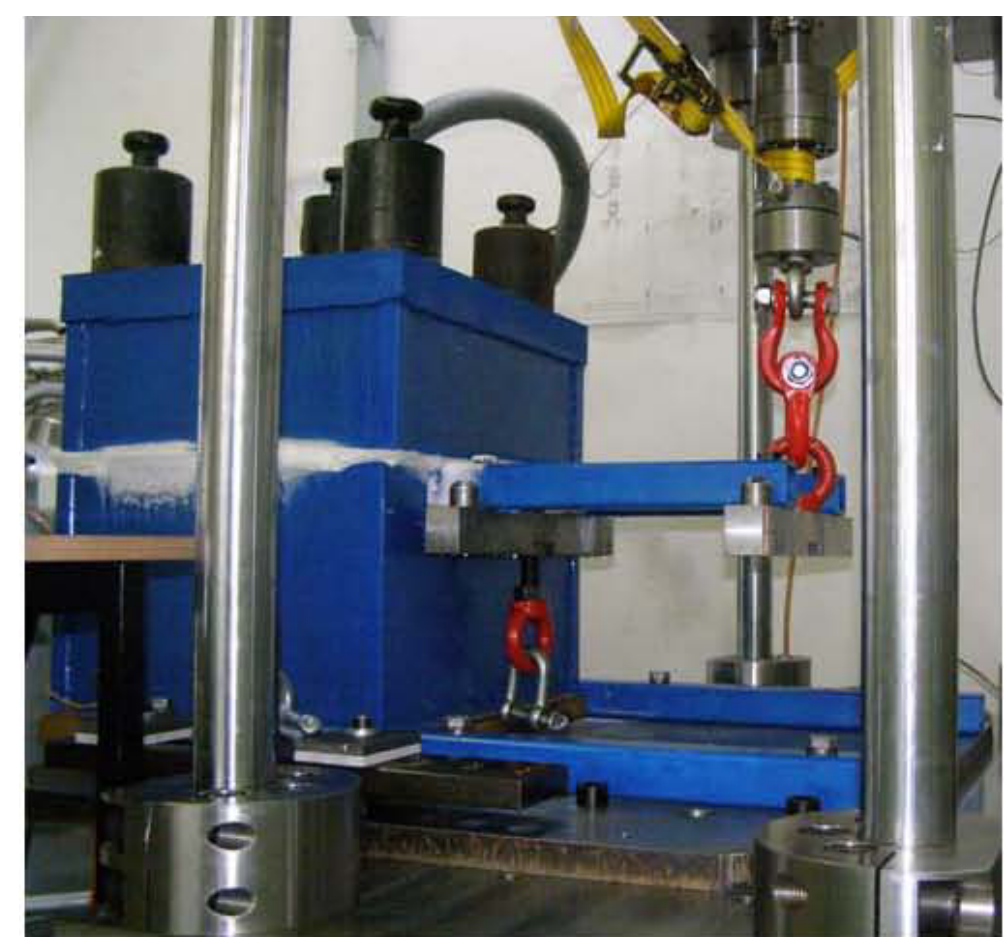

Fig.7 Schematics of test set-up at $77 \mathrm{~K}$ for the parameters mentioned in table 3.

\section{Test results for measurements at $\mathrm{RT}$ and $77 \mathrm{~K}$}

\subsection{Results for RT measurement}

The time dependence of forces applied in axial direction $(F)$ and tangential direction $\left(\mathrm{F}_{\mathrm{Mz}}\right)$ in five steps is shown in figure 8 and the corresponding displacement is shown in figure 9. The displacement values do not show plastic deformations in any of the five load cycles.

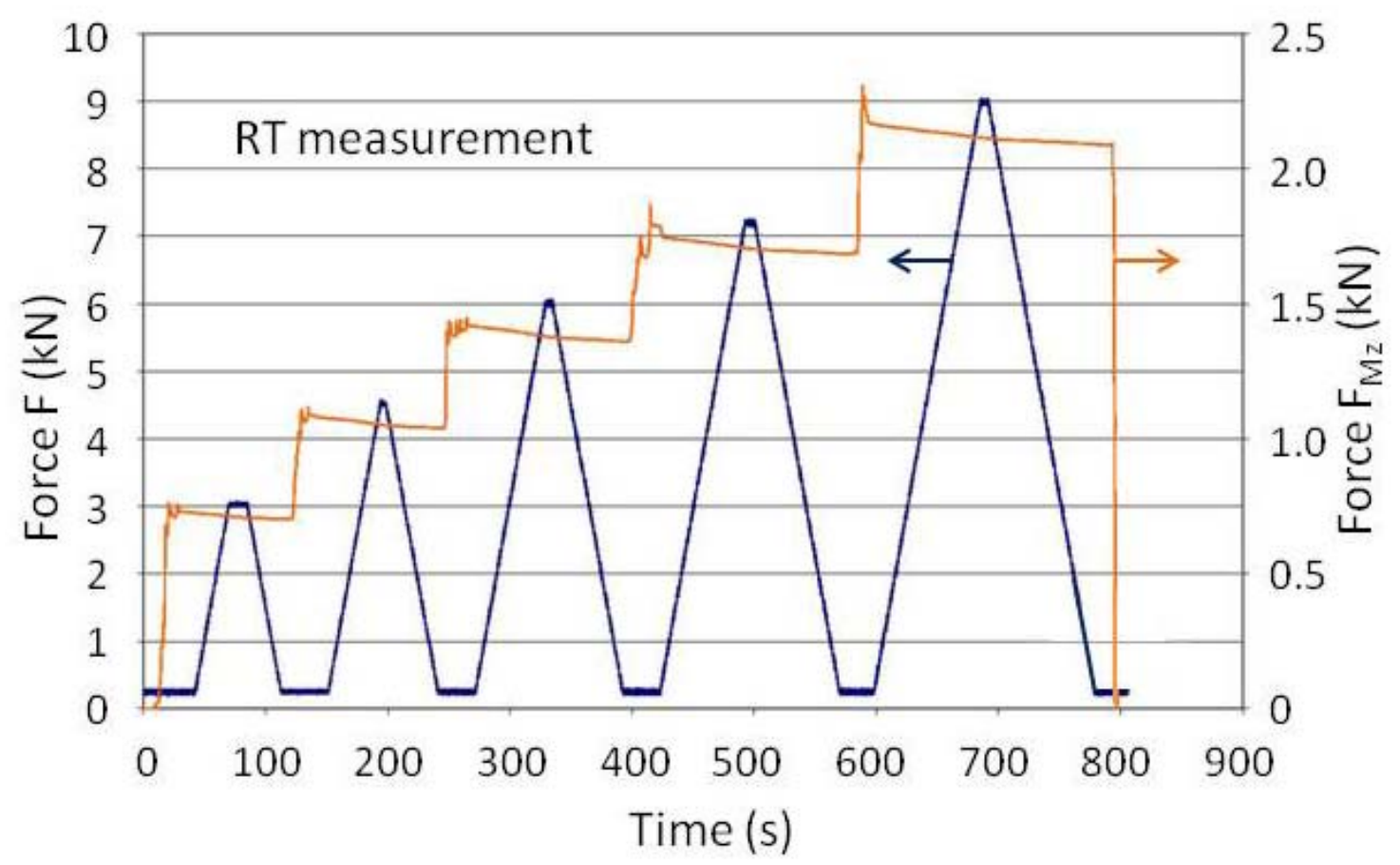

Fig.8 Time variation of forces applied on test piece. 
The small fluctuations in the displacement are due to the small initial adjustment on the loading cylinders at the beginning of each load cycle at $250 \mathrm{~N}$.

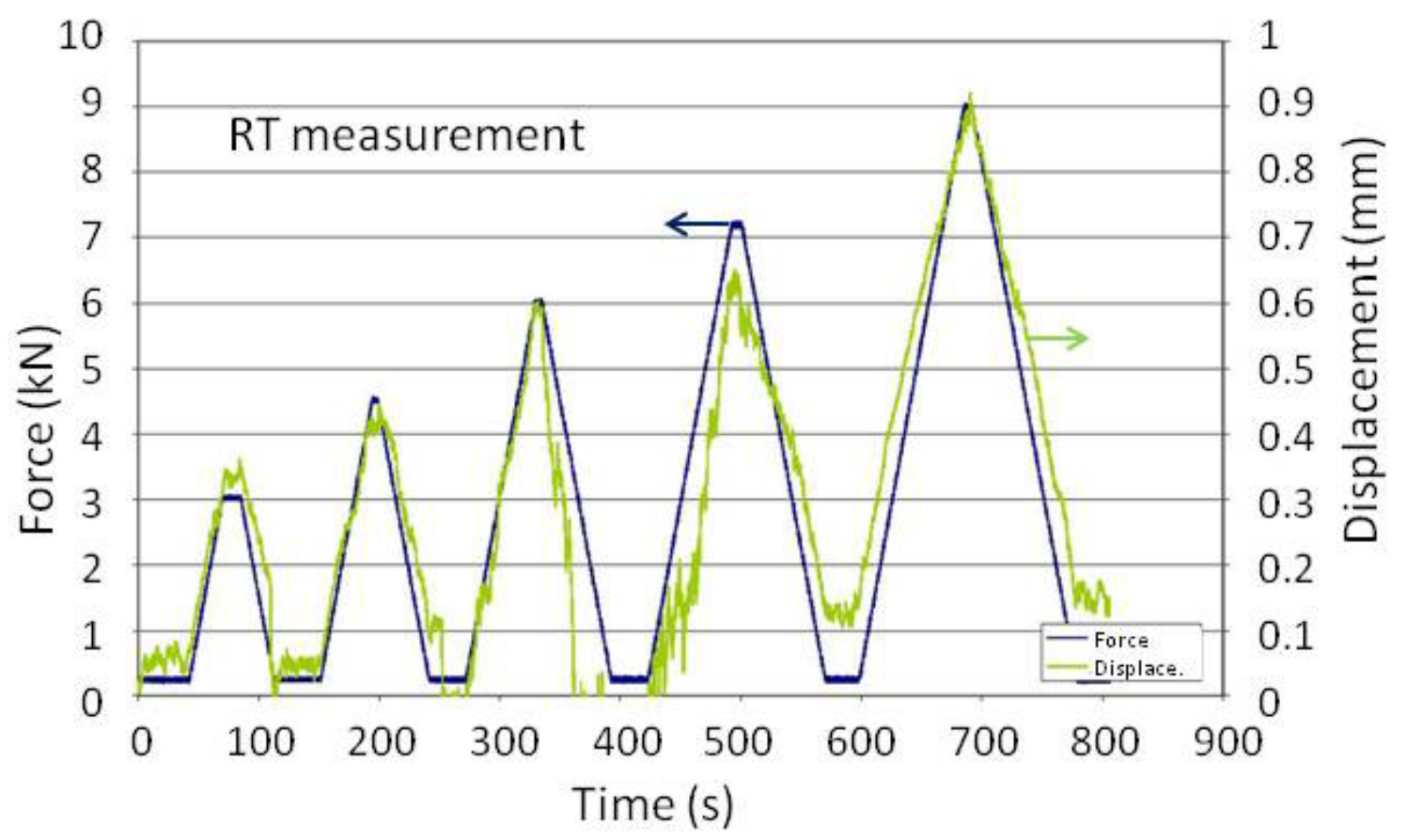

Fig.9 Variation of displacement at applied forces at RT.

\subsection{Results for $77 \mathrm{~K}$ measurement}

For measurements at $77 \mathrm{~K}$, the cool down using LN2 was achieved within $15 \mathrm{~h}$ with the average cooling rate

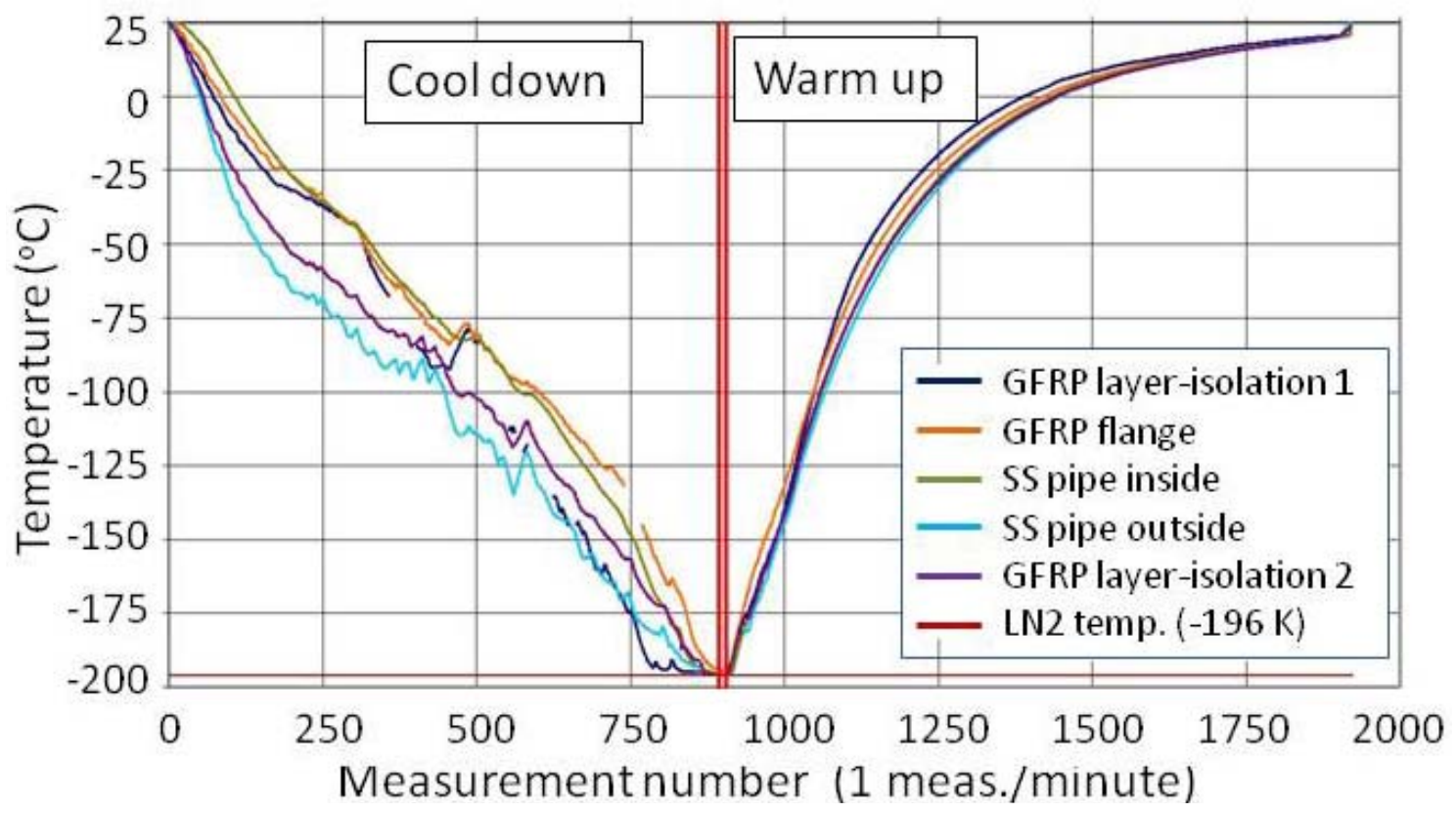

Fig.10 Cool down and warm up of test piece.

of $14.8 \mathrm{~K} / \mathrm{h}$. The temperature difference across the test piece was maintained within $40 \mathrm{~K}$ to keep the thermal stresses with the acceptable limits. After the load test, the warm up was achieved within $16 \mathrm{~h}$. The variation of temperatures at five different locations on the test piece is shown in figure 10. The displacement for the five increasing load cycles as 
per the maximum loads mentioned in table 3, is presented in figure 11 . The displacement follows the load cycle remaining within the elastic limits of the glue joint.

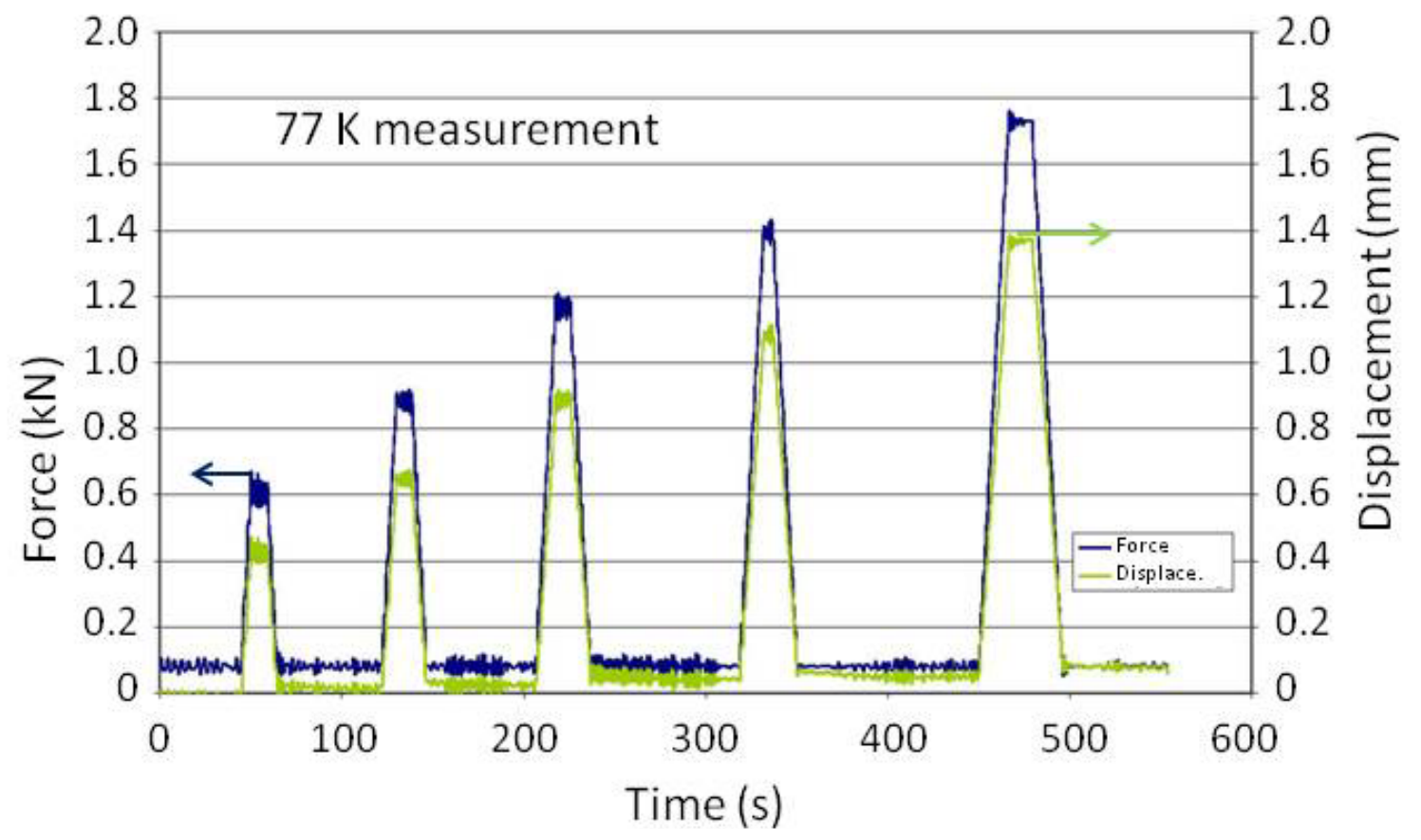

Fig.11 Variation of displacement with forces at 77K.

\section{Conclusions}

The FE analysis showed that due to the difference in thermal contraction coefficient of the GFRP layer and SS, during cooling down the resulting stresses could be critical for this joint. Following the thermal cycling from RT to 77 $\mathrm{K}$, the helium leak test and the Paschen tests did not show any sign of damages. During the mechanical tests at RT and $77 \mathrm{~K}$, the displacements were found to be within the elastic limits without any deformations or visible cracks. The helium leak test and the Paschen test at the end of mechanical tests too did not show any sign of decoupling of the glue joint. Thus it was decided to implement it for the actual leads manufacturing.

\section{Acknowledgments}

Authors would like to thank the company's Marti Supratech AG, Wallisellen, Switzerland, for supply of test pieces flange assembly, Institut fuer Luft- und Kaeltetechnik GmbH, Dresden Germany for thermal cycling, IMA Materialforschung und Anwendungstechnik GmbH, Dresden Germany for the execution of the thermo-mechanical tests and modeling and KIT Karlsruhe for their support.

\section{References}

[1] D. Zacharias, M. Koeppen, Analysis of fixing box structure, IPP internal report 1-GE-T0004 (2007).

[2] V. Bykov et al, Fusion Eng. and Design 86, 645 (2011) and references therein.

[3] T. Guenther, A. Tost, Current lead flange-Calculation and test, IPP internal report 1-ABF05-T3005.0 (2010). 